\title{
Coronary Blood Flow and Lactate Metabolism during Isometric Handgrip Exercise in Heart Disease
}

\author{
Ryo Katori, M.D., Kozui Mryazawa, M.D., Shigeaki Ikeda, \\ M.D., Kunio Shrrato, M.D., Itaru Muraguchi, M.D., \\ and Takeo Hayashi, M.D.
}

\begin{abstract}
SUMMARY
Twenty-one patients with various heart diseases undergoing the coronary sinus catheterization had myocardial blood flow studies before and during isometric handgrip exercise. At $30 \%$ of the maximal voluntary contraction (MVG), handgrip increased both coronary sinus blood flow by $19.8 \%$ and myocardial $\mathrm{O}_{2}$ consumption by $21.0 \%$ on the average as compared to those at rest. At $20 \%$ of $\mathrm{MVC}$, the increase of the both was slight except for 1 case. The increase in coronary sinus blood flow significantly correlated to the increase of myocardial $\mathrm{O}_{2}$ consumption. Lactatc extraction ratio decreased to less than $10 \%$ during handgrip in 4 of 19 cases studied despite of normal values at rest. Lactate extraction ratio had significantly positive correlations with coronary sinus blood flow and myocardial $\mathrm{O}_{2}$ consumption during handgrip, while there were not significant ones at rest. It is suggested that isometric handgrip exercise is useful as a stress test for detection of myocardial ischemia in the heart of coronary artery disease.
\end{abstract}

\section{Additional Indexing Words:}

Coronary sinus flow Dye-dilution method Myocardial ischemia Myocardial oxygen consumption

I

SOMETRIC handgrip exercise has been used as a stress test for estimating cardiac reserve of the left ventricle. ${ }^{1)-10}$ Since handgrip exercise results in increased heart rate, elevated systemic blood pressure, increased cardiac output and presumably enhanced myocardial contractility, myocardial oxygen consumption must be increased ${ }^{11)-13)}$ and myocardial blood flow is inevitably augmented during the exercise. In this point, handgrip exercise might be considered as a useful stress test for detection of myocardial ischemia and diagnosis of ischemic heart disease in cases in whom coronary artery disease is suspected. There is a few reports ${ }^{14), 15)}$ concerning electrocardiographic

From the First Department of Internal Medicine, Kinki University School of Medicine, Osaka and First Department of Internal Medicine, Tohoku University School of Medicine, Sendai, Japan.

Address for reprint request: Ryo Katori, M.D., First Department of Internal Medicine, Kinki University School of Medicine, Sayama-cho, Minami-kawachi-gun, Osaka 589, Japan.

Received for publication January 30, 1976. 
study and occurrence of anginal pain during handgrip exercise, in which the authors ${ }^{14-16}$ ) pointed out that handgrip exercise was inferior to dynamic exercise regarding diagnosis of ischemic heart disease. Coronary circulation study including measurements of myocardial blood flow during handgrip exercise is to our knowledge, only made by Kivowitz et al, ${ }^{2)}$ Lowe et al, ${ }^{16}$ ) and Nelson et al. ${ }^{17}$ )

The purpose of this report is to describe the results of measurements of coronary sinus blood flow and lactate metabolism before and during isometric handgrip exercise in patients with heart diseases.

\section{Materials AND Methods}

Twenty-one patients listed in Table I underwent study. Diagnosis was made by clinical signs, laboratory findings, routine cardiac catheterization, angiocardiography, and selective coronary arteriography when needed.

Studies were performed under the postabsorptive state in supine position on

Table I. Subject

\begin{tabular}{|c|c|c|c|c|c|c|}
\hline Subject & Age & Sex & Diagnosis & NYHA & $\begin{array}{l}\mathrm{BSA} \\
\left(\mathrm{m}^{2}\right)\end{array}$ & $\begin{array}{c}\text { CTR } \\
(\%)\end{array}$ \\
\hline F.O. & 54 & M & Angina Pectoris & 2 & 1.60 & 45 \\
\hline J. S. & 45 & M & Angina Pectoris & 2 & 1.51 & 44 \\
\hline Y.M. & 46 & $F$ & Angina Pectoris & 2 & 1.66 & 44 \\
\hline C. A. & 32 & M & PMD, COCM & 2 & 1.63 & 50 \\
\hline M. H. & 31 & $\mathbf{M}$ & PMD, HCM & 2 & 1.83 & 57 \\
\hline S. F. & 49 & $\mathrm{~F}$ & Mitral Stenosis, AF & 2 & 1.34 & 55 \\
\hline Se. S. & 30 & $F$ & Mitral Stenosis & 2 & 1.51 & 61 \\
\hline Si. S. & 34 & $\mathrm{~F}$ & Mitral Stenosis, AF & 2 & 1.37 & $53:$ \\
\hline H. T. & 52 & $\mathrm{~F}$ & Mitral Stenosis & 3 & 1.47 & 68 \\
\hline C. S. & 54 & M & Mitral Stenosis $\overline{\mathbf{c}}$ Insufficiency & 1 & 1.65 & 50 \\
\hline A. U. & 29 & $\mathrm{~F}$ & Aortic Stenosis, Mitral Insuf. & 2 & 1.28 & 56. \\
\hline H. H. & 18 & $\mathbf{F}$ & Ventricular Septal Defect & 1 & 1.40 & 50 \\
\hline M. N. & 24 & M & Ventricular Septal Defect & 1 & 1.70 & 46. \\
\hline N. K. & 19 & $\mathrm{~F}$ & Atrial Septal Defect & 2 & 1.60 & 51 \\
\hline S. O. & 46 & M & Essential Hypertension & 2 & 1.68 & 46. \\
\hline M. M. & 24 & $M$ & Normal & 1 & 1.57 & 47 \\
\hline H. M. & 61 & $F$ & Angina Pectoris & 2 & 1.34 & 54 \\
\hline S. A. & 59 & M & Myocardial Infarction & 3 & 1.53 & 64 \\
\hline K. I. & 23 & M & PMD, COCM & 2 & 1.68 & 48 \\
\hline M. K. & 44 & M & Mitral Stenosis & 2 & 1.68 & 50 \\
\hline R.A. & 14 & M & Ventricular Septal Defect & 1 & 1.61 & 47 \\
\hline
\end{tabular}

PMD : primary myocardial disease, COCM : congestive type, HCM : hypertrophic type, BSA : body surface area, CTR: cardio-thoracic ratio. 
the X-ray table. Coronary sinus blood flow was measured as described previously. ${ }^{19)}$ The procedures are summarized as follows. A Gensini 9 F catheter was percutaneously introduced via the right femoral vein and advanced until its tip lay in the coronary sinus. A polyethylene tube (I.D., $0.58 \mathrm{~mm}: \quad$ O.D., $0.97 \mathrm{~mm}$ ) was introduced through the catheter and the tip of the tube was advanced more than $5 \mathrm{~cm}$ from the tip of the catheter. A solution of Cardiogreen $395 \mathrm{mg}$ per liter dissolved in isotonic saline was injected into the great cardiac vein through the tube at a constant rate of $7.6 \mathrm{ml}$ per minute with a Harvard infusion withdrawal pump (Model 600-915). While blood was drawn through the catheter with this pump at a constant rate of $20 \mathrm{ml}$ per minute, the dye concentration curve was recorded with a Gilford densitometer (Model 103 IR). Calibration was made by passing known concentrations of dye-labelled blood through the densitometer. Coronary sinus blood flow was calculated from a dye concentration plateau constructed on the dye concentration curve from the coronary sinus using the following formula:

Coronary sinus blood flow $(\mathrm{ml} / \mathrm{min})=\left(\mathrm{C}_{\mathrm{i}}-\mathrm{C}_{\mathrm{p}}\right) \times \mathrm{f} / \mathrm{C}_{\mathrm{p}}$ where $\mathrm{C}_{1}$ represents the dye concentration $(\mathrm{mg} / \mathrm{L})$ of the injectate, $\mathrm{C}_{\mathrm{p}}$ is the dye concentration of the plateau $(\mathrm{mg} / \mathrm{L})$, and $\mathrm{f}$ is the rate of injection $(\mathrm{ml} / \mathrm{min})$.

The position of the catheter was confirmed by injection of contrast medium through the catheter so that it was placed as near to the ostium of the coronary sinus as possible. Furthermore, in order to confirm that the blood drawn through the tip of the catheter was not contaminated with the blood from the right atrium, $5 \mathrm{mg}$ of Cardiogreen was suddenly injected into the femoral vein while recording dye dilution curve from the catheter in the coronary sinus. If there was right atrium contamination, as evidenced by an early appearance of dye, the tip of the catheter was inserted about half a centimeter further into the coronary sinus and the contamination test was repeated. Measurement of coronary sinus blood flow was performed only when the presence of right atrium contamination was excluded.

A Kifa red catheter $25 \mathrm{~cm}$ in length was introduced in the right femoral artery for measurement of arterial blood pressure and cardiac output by the dye-dilution technique with a cuvette densitometer (Gilford Model 103 IR). Cardiac output was measured by injection of Cardiogreen $5 \mathrm{mg}$ into the left antecubital vein and recording of the dye-dilution curve from the femoral artery. In cases with left-toright shunt, shunted blood flow was calculated by Nakamura's method ${ }^{18)}$ and aortic blood flow was obtained by subtraction of shunted blood flow from pulmonary blood flow.

Isometric handgrip exercise was performed by the right hand at 30\% (in 16 patients) or $20 \%$ (in 5 patients) of the maximal voluntary contraction (MVC) using a commercial handgrip dynamometer (Matsuyoshi, Type $M$, Tokyo) for 4 min. All patients were instructed to breathe normally to avoid performing the Valsalva maneuver. ECG was continuously monitored and systemic blood pressure was recorded at interval of $1 \mathrm{~min}$. Coronary sinus blood flow was measured at $3 \mathrm{~min}$ after onset of the exercise, and subsequently cardiac output measurement and blood samplings from the coronary sinus and femoral artery were made. The bloods were analysed for $\mathrm{O}_{2}$ content, $\mathrm{O}_{2}$ saturation and lactate ${ }^{201}$ concentration. Myocardial $\mathrm{O}_{2}$ consumption was calculated by the equation; coronary sinus blood flow $\times$ (arterial $\mathrm{O}_{2}$ content - coronary sinus $\mathrm{O}_{2}$ content). Myocardial lactate ex- 
tration ratio was obtained by the equation; [(arterial blood lactate-coronary sinus blood lactate)/arterial blood lactate $] \times 100$.

\section{RESULTS}

\section{I. $30 \%$ handgrip of MVC (Table II)}

Heart rate and systemic blood pressure increased during handgrip in all cases. The average increase was $16 \pm 11$ beats $/$ min (mean $\pm \mathrm{SD}, \mathrm{p}<0.001$ ) for heart rate, $22 \pm 16 \mathrm{mmHg}(\mathrm{p}<0.001)$ for systolic blood pressure, $18 \pm 9$ $\mathrm{mmHg}(\mathrm{p}<0.001)$ for diastolic blood pressure, and $22+9 \mathrm{mmHg}(\mathrm{p}<0.001)$ for mean blood pressure. Cardiac output did not change significantly. Coronary sinus blood flow increased in all cases, the average increase being $28 \pm 26 \mathrm{ml} / \mathrm{min}(19.8 \%)(\mathrm{p}<0.001)$. Myocardial $\mathrm{O}_{2}$ consumption increased in all cases except for 2 cases; the increase was $2.7 \pm 2.9 \mathrm{ml} / \mathrm{min}(21.0 \%)$ on the average $(\mathrm{p}<0.001)$. Myocardial $\mathrm{O}_{2}$ extraction showed no significant change. Myocardial lactate extraction ratio decreased in 8 of 14 cases and showed lower values than $10 \%$ in 2 cases.

\section{II. $20 \%$ handgrip of MVC (Table III)}

Twenty $\%$ handgrip exercise resulted in less changes in heart rate and blood pressure than $30 \%$ handgrip did. The average increase during the exercise was $2 \pm 2$ beats/min for heart rate, $3 \pm 3 \mathrm{mmHg}$ for systolic pressure, $3 \pm 7 \mathrm{mmHg}$ for diastolic pressure, and $6 \pm 8 \mathrm{mmHg}$ for mean pressure. Cardiac output did not change significantly. Coronary sinus blood flow and myocardial $\mathrm{O}_{2}$ consumption showed only small changes except for 1 (K.I.) who showed large increases in both. Myocardial lactate extraction ratio decreased in 3 cases, increased in 1, and was unchanged in the other one. Two cases had the extraction ratio less than $10 \%$ during handgrip.

III. Relationships between changes in coronary sinus blood flow and in other parameters in response to handgrip exercise (Table IV)

The increase in coronary sinus blood flow revealed a significantly positive correlation with the increase in myocardial $\mathrm{O}_{2}$ consumption during handgrip exercise $(r=0.546, p<0.02)$. Fig. 1 shows the relationship between coronary sinus blood flow and myocardial lactate extraction ratio. Fig. 2 indicates the relationship between myocardial $\mathrm{O}_{2}$ consumption and the lactate extraction ratio. In both figures, the left panel shows the relation before the exercise and the right panel during the exercise. Coronary sinus blood flow was not significantly correlated to myocardial lactate extraction ratio before the exercise $(r=-0.295$, N.S.), while both positively correlated 
Table II. Hemodynamic and Myocardial Blood Flow Response to Isometric Handgrip Exercise. I. $30 \%$ of Maximal Voluntary Contraction of Handgrip

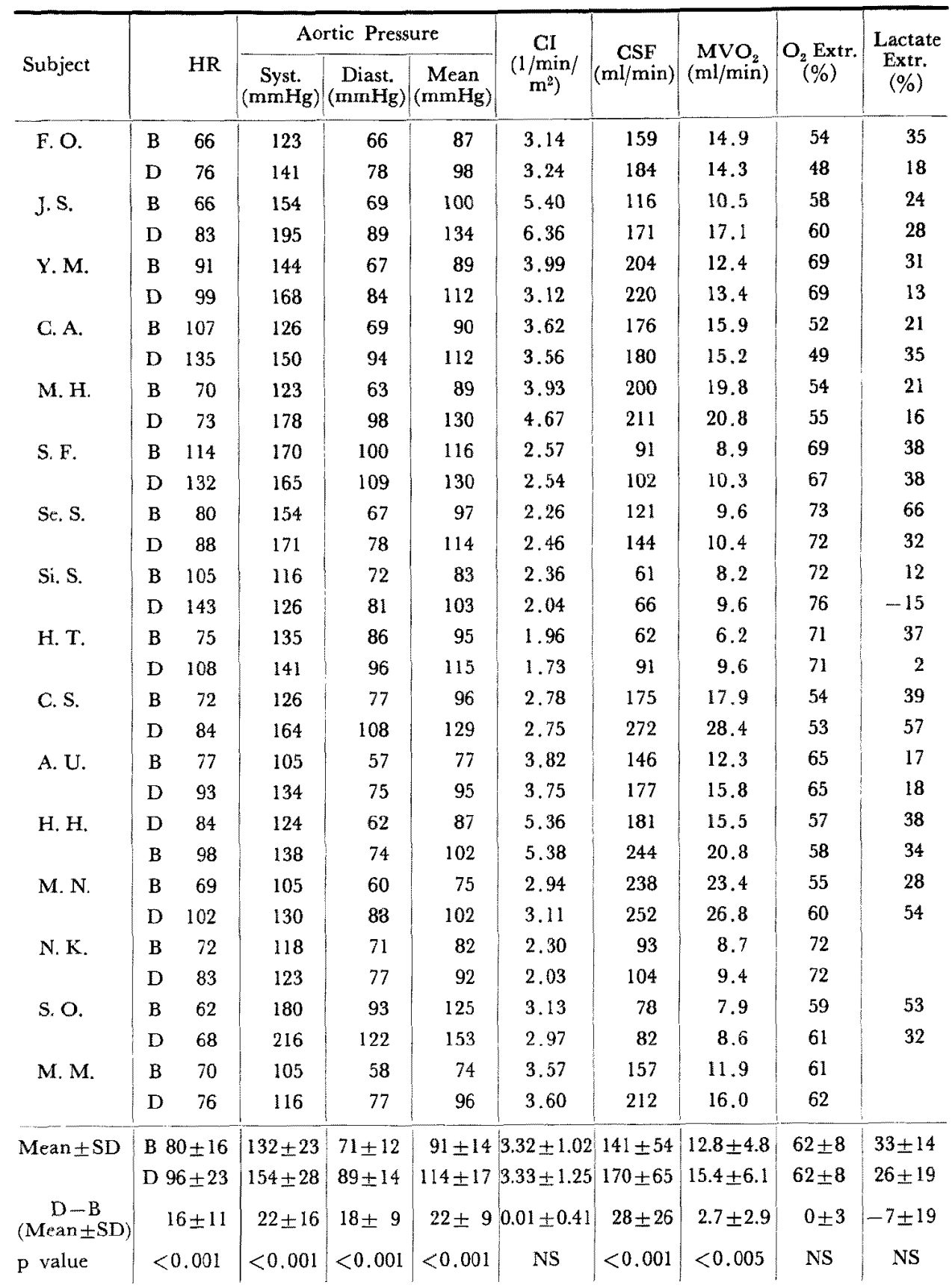

$\mathrm{HR}$ : heart rate, $\mathrm{CI}$ : cardiac index, $\mathrm{CSF}$ : coronary sinus blood flow, $\mathrm{MVO}_{2}$ : myocardial oxygen consumption, $\mathrm{O}_{2}$ Extr.: oxygen extraction ratio, Lactate Extr.: lactate extraction ratio, $\mathrm{B}$ : before handgrip exercise, D: during handgrip exercise. 
Table III. Hemodynamic and Myocardial Blood Flow Response to Isometric Handgrip Exercise. II. 20\% of Maximal Voluntary Contraction of Handgrip

\begin{tabular}{|c|c|c|c|c|c|c|c|c|c|c|}
\hline \multirow[b]{2}{*}{ Subject } & \multirow{2}{*}{\multicolumn{2}{|c|}{$\mathrm{HR}$}} & \multicolumn{3}{|c|}{ Aortic Pressure } & \multirow{2}{*}{$\underset{\substack{\left(1 / \mathrm{min} \\
\mathrm{m}^{2}\right)}}{\mathrm{CI}}$} & \multirow{2}{*}{$\begin{array}{c}\mathrm{CSF} \\
(\mathrm{ml} / \mathrm{min})\end{array}$} & \multirow{2}{*}{$\begin{array}{c}\mathrm{MVO}_{2} \\
(\mathrm{ml} / \mathrm{min})\end{array}$} & \multirow{2}{*}{$\underset{(\%)}{\mathrm{O}_{2} \text { Extr. }}$} & \multirow{2}{*}{$\begin{array}{c}\text { Lactate } \\
\text { Extr. } \\
(\%)\end{array}$} \\
\hline & & & $\begin{array}{c}\text { Syst. } \\
(\mathrm{mmHg})\end{array}$ & $\begin{array}{c}\text { Diast. } \\
(\mathrm{mmHg})\end{array}$ & $\begin{array}{c}\text { Mean } \\
(\mathrm{mmHg})\end{array}$ & & & & & \\
\hline \multirow[t]{2}{*}{ H. M. } & B & 66 & 134 & 75 & 95 & 2.58 & 77 & 5.4 & 54 & 28 \\
\hline & D & 70 & 137 & 71 & 93 & 2.85 & 82 & 7.1 & 63 & -11 \\
\hline \multirow[t]{2}{*}{ S. A. } & B & 100 & 165 & 86 & 106 & 2.55 & 120 & 12.0 & 61 & 14 \\
\hline & D & 100 & 163 & 94 & 117 & 2.42 & 117 & 11.5 & 60 & 14 \\
\hline \multirow[t]{2}{*}{ K. I. } & B & 79 & 131 & 68 & 90 & 5.63 & 298 & 24.2 & 47 & 11 \\
\hline & D & 81 & 132 & 71 & 100 & 5.63 & 424 & 37.6 & 51 & 20 \\
\hline \multirow[t]{2}{*}{ M. K. } & B & 102 & 136 & 82 & 100 & 4.20 & 127 & 13.5 & 55 & 26 \\
\hline & D & 106 & 138 & 77 & 97 & 3.74 & 133 & 13.8 & 55 & 1 \\
\hline \multirow[t]{2}{*}{ R. A. } & B & 64 & 161 & 80 & 102 & 3.72 & 112 & 13.6 & 67 & 41 \\
\hline & $\mathrm{D}$ & 64 & 168 & 90 & 115 & 3.94 & 107 & 10.3 & 62 & 34 \\
\hline \multirow[t]{2}{*}{ Mean $\pm S D$} & B & $82 \pm 18$ & $145 \pm 16$ & $78 \pm 7$ & $99 \pm 6$ & $3.74 \pm 1.28$ & $147 \pm 87$ & $13.7 \pm 6.7$ & $57 \pm 8$ & $24 \pm 12$ \\
\hline & & $84 \pm 18$ & $148 \pm 17$ & $81 \pm 11$ & $104 \pm 11$ & $3.72 \pm 1.24$ & $173 \pm 142$ & $16.1 \pm 12.3$ & $58 \pm 5$ & $12 \pm 17$ \\
\hline $\begin{array}{c}\mathrm{D}-\mathrm{B} \\
(\mathrm{Mean} \pm \mathrm{SD})\end{array}$ & & $2 \pm 2$ & $3 \pm 3$ & $3 \pm 7$ & $6 \pm 8$ & $\begin{array}{r}-0.02 \\
\pm 0.29\end{array}$ & $26 \pm 56$ & $2.3 \pm 6.5$ & $1 \pm 5$ & $-12 \pm 19$ \\
\hline$p$ value & & NS & NS & NS & NS & NS & NS & NS & NS & NS \\
\hline
\end{tabular}

$\mathrm{HR}$ : heart rate, $\mathrm{CI}$ : cardiac index, CSF : coronary sinus blood flow, $\mathrm{MVO}_{2}$ : myocardial oxygen consumption, $\mathrm{O}_{2}$ Extr.: oxygen extraction ratio, Lactate Extr.: lactate extraction ratio, B: before handgrip exercise, $\mathrm{D}$ : during handgrip exercise.

Table IV. Correlation Coefficients between the Increase in Coronary Sinus Flow and Changes in Other Parameters by Isometric Handgrip Exercise

\begin{tabular}{l|c|c}
\hline \multicolumn{1}{c|}{ Parameters } & $\begin{array}{c}\text { Correlation } \\
\text { Coefficient }\end{array}$ & $\begin{array}{c}\text { Significance } \\
\text { (p value) }\end{array}$ \\
\hline Heart Rate & 0.055 & NS \\
Arterial Systolic Pressure & 0.337 & NS \\
Arterial Diastolic Pressure & 0.330 & NS \\
Arterial Mean Pressure & 0.378 & NS \\
Cardiac Index & 0.194 & NS \\
Myocardial Oxygen Consumption & 0.546 & p $<0.02$ \\
Myocardial O Extraction Ratio & -0.012 & NS \\
Myocardial Lactate Extr. Ratio & 0.331 & NS \\
Effort Index & 0.331 & NS \\
Katz's Index & 0.201 & NS
\end{tabular}

Effort index $=$ arterial systolic pressure $\times$ heart rate, Katz's index =arterial mean pressure $\times$ heart rate, NS: not significant. 


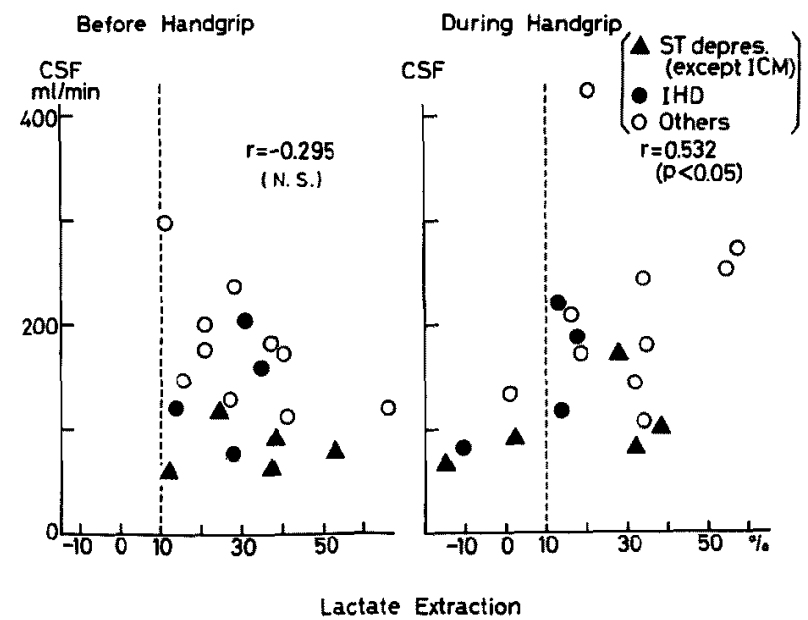

Fig. 1. Relationship between coronary sinus blood flow and lactate cxtraction ratio before and during handgrip. Left panel is before handgrip, and right panel is during handgrip.

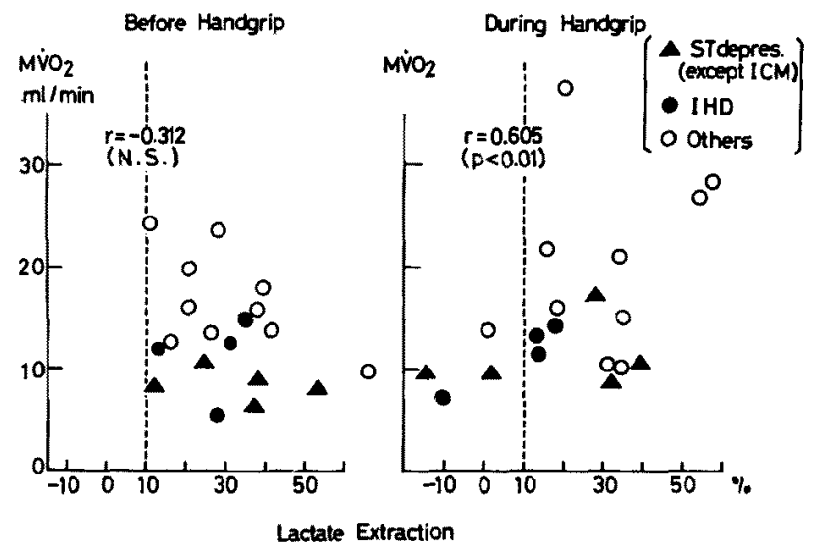

Fig. 2. Relationship between myocardial oxygen consumption and lactate extraction ratio before and during handgrip. Left panel is before handgrip, and right panel is during handgrip.

with each other during the exercise as shown in Fig. $1(r=0.532, p<0.05)$. The similar relation was obtained between myocardial $\mathrm{O}_{2}$ consumption and myocardial lactate extraction ratio as seen in Fig. 2. It was observed that most of patients with ischemic heart disease or ST depression on ECG tended to shift to lactate production during handgrip exercise.

\section{Drscussion}

Isometric handgrip exercise increases heart rate and systemic blood pres- 
sure so that it enhances myocardial oxygen requirement and leads to an increase in myocardial blood flow. ${ }^{2), 16), 17}$ In patients with ischemic heart disease who have a limitation in increasing coronary artery blood flow during exercise, therefore, handgrip exercise would induce ischemia in the myocardium and result in the impairment of left ventricular function due to ischemic changes. The latter is one of the reasons why handgrip exercise has been applied as a stress test for the evaluation of cardiac function.

It has been reported, ${ }^{14), 15)}$ however, that handgrip exercise was less valuable than dynamic exercise, when myocardial ischemia was evaluated by ischemic ECG changes and occurrence of anginal chest pain during exercise. The advantage of handgrip exercise may be simplicity and clinical convenience because this is possible to perform at bedside whenever and wherever it is needed. Some authors ${ }^{1,22), 231}$ reported that occurrence of diastolic heart sound during hadgrip was related to ischemic impairment of left ventricular function. Cohn et $\mathrm{al}^{23}$ ) suggested that the emergence of diastolic heart sounds during handgrip exercise is a useful clinical adjunct in the diagnosis of coronary artery disease and these sounds are associated with significant elevations in left ventricular end-diastolic pressure in patients with coronary artery disease. Flessas et al ${ }^{21)}$ reported that all 8 patients with the increase in left ventricular end-diastolic pressure developed hypokinetic areas during handgrip exercise and the abnormal response to handgrip exercise in patients with coronary artery desease may result from the development of hypokinetic areas that decrease the distensibility of the left ventricle.

The measurement of coronary blood flow during handgrip exercise was for the first time performed by Kivowitz et al. ${ }^{2}$ They reported that coronary sinus blood flow by means of the thermo-dilution technique increased from $123 \pm 9.6 \mathrm{ml} / \mathrm{min}$ to $179 \pm 13.4 \mathrm{ml} / \mathrm{min}$ by $5 \mathrm{~min}$ handgrip exercise at $25 \%$ of MVC in 7 patients with coronary artery disease and in one hypertensive. Lowe et al ${ }^{16}$ measured myocardial blood flow before and during handgrip exercise at $33 \%$ of MVC by means of the ${ }^{84} \mathrm{Rb}$ coincidental counting method in patients with and without coronary artery disease. In their study, myocardial blood flow increased by $35 \%$ on the average in 7 patients without coronary artery disease and by $23 \%$ in 17 patients who had significant coronary disease, i.e., greater than $75 \%$ occlusion of at least one major coronary artery and no angina, while it decreased by $17 \%$ in 6 patients who had both significant coronary disease and angina. Nelson et al ${ }^{17)}$ measured myocardial blood flow during static (handgrip) and dynamic (ergometer) exercise by the $\mathrm{N}_{2} \mathrm{O}$ method in 10 normal subjects, and mean myocardial blood flow increased from $181 \mathrm{ml} / 100 \mathrm{Gm} \mathrm{LV} / \mathrm{min}$ during dynamic exercise only to $201 \mathrm{ml} / 100 \mathrm{Gm}$ $\mathrm{LV} / \mathrm{min}$ during combined static (at $17 \%$ of $\mathrm{MVC}$ ) and dynamic exercise. 
In the present study, coronary sinus blood flow increased by $19.8 \%$ at $30 \%$ of MVG and by $17.6 \%$ at $20 \%$ of $\mathrm{MVC}$, respectively, although in the latter the increase was not significant. Increases in coronary sinus blood flow significantly correlated with increases in myocardial $\mathrm{O}_{2}$ consumption as shown in Table IV, while these had no significant correlation with the other parameters. It has been reported ${ }^{24), 25}$ ) that myocardial blood flow and myocardial $\mathrm{O}_{2}$ consumption increase in proportion to heart rate or the product of heart rate and blood pressure during dynamic exercise. The lack of the above-mentioned relations during handgrip exercise seems due to small increase of heart rate as compared to dynamic exercise.

Myocardial lactate extraction ratio showed no significant change during handgrip exercise as a whole. Kivowitz et al2) reported that there was no significant change of lactate extraction ratio during handgrip exercise at $25 \%$ of MVC in 5 patients with coronary artery disease although lactate concentration increased in both arterial blood and coronary sinus blood. Nakhjavan et al $^{26)}$ reported myocardial lactate metabolic studies done during pacing tachycardia and isometric handgrip at $30 \%$ of MVC. They indicated that isometric handgrip even if performed during pacing tachycardia was not a sensitive test for detection of myocardial lactate abnormality and that the rising level of arterial lactate during isometric handgrip was the most likely mechanism of positive myocardial arteriovenous lactate difference.

There has been no report, to our knowledge, that revealed the relationship between myocardial lactate metabolism and coronary blood flow or myocardial $\mathrm{O}_{2}$ consumption during handgrip exercise. In our study, it is noteworthy that 4 cases showed myocardial lactate production or decreased extraction (less than 10\%) during handgrip exercise despite of normal lactate metabolism at rest. It is, furthermore, interesting that there were significant positive correlations between lactate extraction ratio and coronary sinus blood flow and myocardial $\mathrm{O}_{2}$ consumption during handgrip exercise as shown in the right panel of Figs. 1 and 2. These indicate that isometric handgrip exercise induced myocardial ischemia in the cases who could not increase myocardial blood flow during the exercise. Thus, it may be concluded that isometric handgrip exercise is useful as a stress test for disclosing or aggravating myocardial ischemia in the heart.

\section{ACKNOWLEDGEMENTS}

We acknowledge the technical assistance of Miss Satoko Takahashi. The typing and editorial efforts of Miss Hiroko Kitahama are also gratefully acknowledged. 


\section{REFERENCES}

1. Helfant RH, DeVilla MA, Meister SG: Effect of sustained isometric handgrip exercise on left ventricular performance. Circulation 44: 982, 1971

2. Kivowitz C, Parmley WW, Donoso R, Marcus H, Ganz W, Swan HJC: Effect of sustained isometric exercise on cardiac performance. The grip test. Circulation 44: 994, 1971

3. Krayenbuehl HP, Rutishauser W, Schoenbeck M, Amende I; Evaluation of left ventricular function from isovolumic pressure measurements during isometric exercise. Am $\mathrm{J}$ Cardiol 29: 323,1972

4. Siegel W, Gilbert CA, Nutter DO, Schlant RC, Hurst JW: Use of isometric handgrip for the indirect assessment of left ventricular function in patients with coronary atherosclerotic heart disease. Am J Cardiol 30: 48, 1972

5. Grossman W, McLaurin LP, Saltz SB, Paraskos JA, Dalen JE, Dexter L: Changes in the inotropic state of the left ventricle during isometric cxercise. Brit Heart J 35: 697, 1973

6. Fisher ML, Nutter DO, Jacobs W, Schlant RC: Haemodynamic responses to isometric exercise (handgrip) in patients with heart disease. Brit Heart J 35: 422, 1973

7. Quarry VM, Spodick DH: Cardiac responses to isometric exercise. Comparative effects with different postures and levels of exertion. Circulation 49: 905, 1974

8. Quinones MA, Gaasch WH, Waisser E, Thiel HG, Alexander JK: An analysis of the left ventricular response to isometric exercise. Am Heart J 88:29, 1974

9. Watanabe T, Fu LT, Togo C, Kato K, Koyama S: Studies on handgrip test in heart diseases. I. Ischemic heart disease and hypertension. Shinzo (Heart) 6: 199, 1974 (in Japanese)

10. Miyazawa K, Honna T, Ikeda S, Shirato K, Takahashi R, Shibuya H, Otani S, Hayashi T, Tsuiki K, Ishikawa K, Katori R: Evaluation of left ventricular function during isometric handgrip. Shinzo (Heart) 7:657, 1975 (in Japanese)

11. Sarnoff SJ, Braunwald E, Welch GH Jr, Case RB, Stainly WN, Macruz R: Hemodynamic determinants of oxygen consumption of the heart with special reference to the tension-time index. Am J Physiol 192: 148, 1958

12. Sonnenblick EH, Ross J Jr, Covell JW, Kaiser GA, Braunwald E: Velocity of contraction as a determinant of myocardial oxygen consumption. Am J Physiol 209: 919, 1965

13. Graham TP Jr, Ross J Jr, Covell JW, Sonnenblick EH, Clancy RL: Myocardial oxygen consumption in acute experimental cardiac depression. Circulat Res 21: 123, 1967

14. Helfant RH, Banka VS, DeVilla MA, Pine R, Kabde V, Meister SG: Use of bicycle ergometry and sustained handgrip exercise in the diagnosis of presence and extent of coronary heart disease, Brit Heart J 35: 1321, 1973

15. Haessly JC, Messin R, Desgre S, Vandermoten P, Demaret B, Denolin H: Comparative response to isometric (static) and dynamic exercise tests in coronary disease. Am $\mathrm{J}$ Cardiol 33: 791,1974

16. Lowe DK, Rothbaum DA, McHenry PL, Corya BC, Knoebel SB: Myocardial blood flow response to isometric (handgrip) and treadmill exercise in coronary artery disease. Circulation 51: 126, 1975

17. Nclson RR, Gobcl FL, Jorgensen CR, Wang K, Wang Y, Taylor HL: Hcmodynamic predictors of myocardial oxygen consumption during static and dynamic exercise. Circulation 50: 1179,1974

18. Nakamura T, Katori R, Watanabe Te, Watanabe Ta, Miyazawa K, Murai M, Oda J, Ishikawa $\mathrm{K}$ : Quantitation of left-to-right shunt from a single earpiece dye-dilution curve. J Appl Physiol 22: 1156, 1967

19. Ishikawa K, Miyazawa K, Tsuiki K, Matsunaga A, Haneda $T$, Katori R, Nakamura $T$ : Measurement of coronary sinus blood flow by dye dilution technique in man. $\mathrm{J}$ Lab Clin Med 79: 75, 1972

20. Hohorst JJ: L-lactate. Determination with lactic dehydrogenase and DPN. In: Methods of Enzymatic Analysis, ed Bergmeyer HU, Verlag Chemie, GMBH, Academic Press, New 
York and London, p 266, 1965

21. Flessas A, Sumner R, Naggar G, Keefe J, Ryan TJ: The mechanism of abnormal response to isometric handgrip in patients with coronary heart disease. Circulation 46 (Suppl 2): 106, 1972 (Abstr)

22. Matthews OA, Blomqvist CG, Cohen LS, Mullins CB: Left ventricular function during isometric exercise (handgrip). Significance of an atrial gallop $\left(S_{4}\right)$. Am Heart J 88: 686, 1974

23. Cohn PF, Thompson P, Strauss W, Todd J, Gorlin R: Diastolic heart sounds during static (handgrip) exercise in patients with chest pain. Circulation 47: 1217, 1973

24. Kitamura K, Jorgensen GR, Gobel FL, Taylor HL, Wang Y: Hemodynamic correlates of myocardial oxygen consumption during upright exercise. J Appl Physiol 32: 516, 1972

25. Jorgensen CR, Wang K, Wang Y, Gobel FL, Nelson RR, Taylor HL: Effect of propranolol on myocardial oxygen consumption and its hemodynamic correlates during upright exercise. Circulation 48: 1173, 1973

26. Nakhiavan FK, Natarajan G, Smith AM, Dratch M, Goldberg H: Myocardial lactate metabolism during isometric handgrip test. Comparison with pacing tachycardia. Brit Heart J 37: 79, 1975 